\title{
ASOSIASI FUNGI MIKORIZA ARBUSKULA (FMA) PADA BERBAGAI TINGGI SEMAI PERMUDAAN ALAM NYAMPLUNG (Calophyllum inophyllum L) DI KABUPATEN KETAPANG
}

\author{
(Association of Arbuscular Mycorrhizal Fungi on Various Height of Natural Regeneration \\ Seedling (Calophyllum inophyllum L) inKetapang District)
}

\author{
Afni Fitriani \\ Fakultas Kehutanan Universitas Tanjungpura Jalan Imam Bonjol Pontianak 78124 \\ Email: afnifitriani98@gmail.com
}

\begin{abstract}
Nyamplung (Calophyllum inophyllum L) is known to be associated with AMF, but it is still unknown whether the association has begun to occur when cotyledons are still present or starting at a certain level of regeneration. Research has been done in Pecal Beach Kinjil River in Ketapang district. The purposes of the research are: (1) to assess the amount of spores and genus AMF associated with its development in the rhizosphere of nyamplung regeneration nature seedling stage from $10 \mathrm{~cm}$ to $150 \mathrm{~cm}$, and (2) to determine root infection percentage in order to know the level of the association at any size of penage regeneration seedlings. The research is a field research by survey method with sampling technique against natural regeneration seedling level of $10 \mathrm{~cm}, 30 \mathrm{~cm}, 60 \mathrm{~cm}, 90 \mathrm{~cm} 120 \mathrm{~cm}$, and $150 \mathrm{~cm}$. The data was collectedin laboratoryon the form of the number of spores and genus AMF and the percentage of infections in the roots. The research results showed that there were 616 AMF spores fruit $/ 100 \mathrm{~g}$ of sandy soil consisting of the genus Glomus (597 pieces / $100 \mathrm{~g}$ sandy soil), Gigaspora ( 15 pieces / $100 \mathrm{~g}$ sandy soil) and Scutellospora ( 4 pieces / $100 \mathrm{~g}$ sandy soil). The development of the number of spores increased from the height of the seedling's natural regeneration measuring was $10 \mathrm{~cm}$ to $150 \mathrm{~cm}$. The results of observations on the roots found thatAMF infection is in the form of vesicles and arbuscular. Infection at the root of natural penage regeneration from $84.44-100 \%$, indicating the level of association between AMF and nyamplung seedling's natural regeneration in the high class ( grade 5 ).
\end{abstract}

Keywords: Arbuscular Mycorrhizal Fungi (AMF) Nyamplung (Calophyllum inophyllumL)

Natural Seedling Regeneration, Pecal Beach.

\section{PENDAHULUAN}

Tanaman nyamplung yang dengan nama lokal penage (Calophyllum inophyllum L) sudah banyak dikenal oleh masyarakat pesisir Kalimantan Barat.Salah satu manfaat kayunya digunakan sebagai bahan pembuatan perahu (Muin dkk. 2011). Hasil penelitin Muin dkk.(2011) dan Priyanto (2013) di Kabupaten Kayong
Utaraterdapat sebanyak 290 pohon nyamplungdengan kadar minyak kotor yang cukup tinggi yakni berkisar antara 58-65\% per kilogram biji kering. Kadar minyak yang cukup tinggi ini dapatdimanfaatkan sebagai bahan bakar nabati atau biodisel (Muin dkk.2011). Dalam penelitian Muin (2018) telah menemukan tanaman penage di daerah 
pesisirpantai Pecal desa Sungai Kinjil kabupaten Ketapang. Menurutnya tanaman nyamplung tersebut tumbuh subur secara alam pada tanah berpasir dengan kondisi permudaan alam yang cukup berlimpah. Pohon nyamplung yang terdapat di Kabupaten Kayong Utara dan Ketapang tersebut hanya terbatas tumbuh di daerah pesisir, sehingga menurut Muin dkk. (2011) dan Priyanto (2013), perlu dilakukan peremajaan dan perluasan tanaman, terutama habitat di luar daerah berpasir.

Umumnya tanah berpasir memiliki sedikit unsur hara yang menyebabkantanaman sulit tumbuh dan berkembang dengan baik. Meskipun nyamplung tumbuh pada daerah berpasir, namun terlihat tanaman bisa tumbuh dengan subur. Salah satu cara agar tanaman tersebut dapat hidup pada tanah yang tidak subur, yaitu berasosiasi dengan fungi mikoriza termasuk fungi mikoriza arbuskula (FMA). Penelitian Burhanuddin dkk. (2012) telah menemukan bahwa nyamplung bersimbiosis dengan FMA. Hasil penelitian Tolosang (2011) menunjukkan bahwa pada setiap sampel tanah nyamplung yang diambil di daerah pesisir Pulau Dato kabupaten Kayong Utara telah ditemukan beberapa genus spora FMA pada rhozisfer dan infeksi FMA pada akar tanaman nyamplung. Meskipun sudah diketahui bahwa tanaman nyamplungberasosiasi dengan FMA, namun hasil penelitian tersebut belum menentukan pada tingkat pertumbuhan bagaimana asosiasi tersebut sudah mulai terjadi terutama pada permudaan alam nyamplung tingkat semai. Apakah asosiasi tersebut sudah mulai terjadi ketika permudaan alam masih memiliki kotiledonnya atau dimulai pada ukuran tinggi permudaan tertentu. Permasalahan lainnya bagaimana perkembangan tingkat asosiasi FMA pada berbagai ukuran tinggi permudaan alam penage tingkat semai ditinjau dari jumlah spora yang terdapat pada rhizosfer dan genus fungi mikoriza yangberasosiasi serta persen infeksi pada akarnya. Berdasarkan permasalahan tersebut, maka perlu dikaji mengenai asosiasi fungi mikoriza arbuskula pada berbagai ukuran tinggi tingkat semai permudaan alam nyamplungdi daerah pesisir pantai Pecal desa Sungai Kinjil kabupaten Ketapang.

Tujuan penelitian yaitu: (1) mengkaji jumlah spora dan genus FMA yang berasosiasi serta perkembangannya pada rhizosfer permudaan alam tingkat semai nyamplung mulai dari tinggi $10 \mathrm{~cm}$ sampai $150 \mathrm{~cm}$, dan (2) menentukan persen infeksi akar sehingga diketahui tingkat asosiasi pada setiap ukuran tinggi semai permudaan alam nyamplung.Hasil penelitian ini diharapkan dapat dijadikan sebagai acuandalam menentukan teknik inokulasiFMA untuk budidaya tanaman nyamplung.

\section{METODE PENELITIAN}

Penelitian dilaksanakan selama 4 minggu di 3 lokasi, yaitu (1) di daerah pesisir pantai Pecal desa Sungai Kinjil kabupaten Ketapang untuk pengambilan sampel akar dan tanah rizosfer, (2) di Laboratorium Silvikultur FakultasKehutanan UNTANuntuk pengamatan FMA dan (3) di Laboratorium Kimia dan Kesuburan TanahFakultas 
Pertanian UNTAN untuk analisis tanah berpasir berupa $\mathrm{pH}$ dan unsur hara Nitorogen (N-total), $\mathrm{P}\left(\mathrm{P}_{2} \mathrm{O}_{5}\right)$ dan Kalium (K) sebagai data penunjang .Proses pengambilan sampel akar dan tanah rizosfer di lapangan dilakukan menggunakan metode survei dengan teknik sampling terhadappermudaan alamtingkat semai ukuran $10 \mathrm{~cm}, 30 \mathrm{~cm}$, $60 \mathrm{~cm}, 90 \mathrm{~cm} 120 \mathrm{~cm}$, dan $150 \mathrm{~cm}$.Setiap tinggi permudaan tingkat semai diambil sebanyak tiga sampel tanah sampai kedalaman $30 \mathrm{~cm}$ yang dikompositkan dan tiga sampel akar pada setiap tinggi permudaan alam tingkat semai, sehingga total keseluruhan sampel tanah dan akar masing-masing sebanyak 18 sampel.Data yang dikumpulkan dari proses pengamatan FMA berupa jumlah spora/100 g tanah berpasir dan genus FMA serta persen infeksi dalam akar. Pengamatan spora dilakukan dengan teknik saring basah (Brundrett et al. 1994) dan identifikasi dilakukan sampai tingkat genus dengan memperhatikan bentuk, warna, ornamen spora. Sedangkan proses infeksi pada akar dalam penelitian ini dilakukan dengan metode sistematik, yaitu metode slide (Muin 2009).Persen infeksi ditentukan berdasarkanperbandingan akar yang terinfeksi dengan jumlah seluruh potongan akar yang diamati. Tingkat infeksi ditentukan melalui The Institute of Mycorrizal Research and Development, USDA Forest Service, Athena, Georgia (Muin 2009) yang terdiri dari 5 kelas, yaitu:

- Kelas 1, Bila infeksinya 0\% - $5 \%$ (Tidak ada asosiasi FMA)

- Kelas 2, Bila infeksinya 6\% - 25\% (Tingkat asosiasi sangat rendah FMA)

- Kelas 3, Bila infeksinya 26\% - 50\% (Tingkat asosiasi FMA rendah)

- Kelas 4, Bila infeksinya 51\% - 75\% (Tingkat asosiasi FMA sedang)

- Kelas 5, Bila infeksinya 76\% - 100\% (Tingkat asosiasi FMA tinggi)

\section{HASIL DAN PEMBAHASAN}

1. Hasil pengamatan jumlah spora dan identifikasi genus spora FMA

Hasil penelitian berupa pengamatan dan identifikasi spora FMA dari 18 sampel pada rhizosfer akar permudaan alam nyamplungtingkat semai $10 \mathrm{~cm}, 30 \mathrm{~cm}, 60$ $\mathrm{cm}, 90 \mathrm{~cm}, 120 \mathrm{~cm}$ dan $150 \mathrm{~cm}$ disajikan pada Tabel 1.Dari hasil penelitian tersebut dapat diketahui bahwa terdapat spora FMA pada rhizosfer permudaan alam tingkat semai nyamplung yang tumbuh di pesisir pantai Pecal Desa Sungai Kinjil Kabupaten Ketapang. 
Tabel 1. Rata-rata jumlah spora/100g tanah berpasirpada permudaan alam nyamplung tingkat semai (The average number of spores/100 $\mathrm{g}$ of sandy soil on nyamplung regeneration on seedling level).

\begin{tabular}{|c|c|c|c|c|c|c|c|}
\hline \multirow{3}{*}{ Ulangan } & \multicolumn{6}{|c|}{ Rata-rata spora FMA / 100 g tanah berpasir } & \multirow{3}{*}{$\begin{array}{l}\text { Rata- } \\
\text { rata }\end{array}$} \\
\hline & \multicolumn{6}{|c|}{ Tinggi Semai (cm) } & \\
\hline & 10 & 30 & 60 & 90 & 120 & 150 & \\
\hline 1 & 247 & 320 & 865 & 337 & 381 & 444 & 432 \\
\hline 2 & 326 & 397 & 278 & 779 & 778 & 787 & 558 \\
\hline 3 & 401 & 584 & 687 & 907 & 1011 & 1567 & 859 \\
\hline $\begin{array}{l}\text { Rata- } \\
\text { rata }\end{array}$ & 325 & 434 & 610 & 673 & 723 & 931 & 616 \\
\hline
\end{tabular}

perhitungan spora FMA yang diambil dari saringan ukuran $125 \mu \mathrm{m}$ dan $63 \mu \mathrm{m}$ menunjukan bahwa semakin tinggi ukuran tinggi permudaan alam nyamplung, jumlah spora FMA semakin bertambah banyak.Pada ukuran tinggi $10 \mathrm{~cm}$ hanya ditemukan sebanyak 325 buah/100 g/ tanah, namun meningkat sampai 931 buah/100 g/tanah pada ukuran tinggi $150 \mathrm{~cm}$. Jumlah spora tersebut semakin banyak dengan bertambahnya ukuran tinggi permudaan tingkat semai. Berdasarkan identifikasi sampai pada tingkat genus dalam Tabel 2, pada rhizosfer permudaan tingkat semai nyamplung ditemukan spora genusGlomus sp sebanyak 597 buah/100 g tanah berpasir, Gigasphora sp15 buah/100 g tanah berpasir dan Scutellospora sp 4 buah/100 g tanah berpasir.

Tabel 2. Rata-rata jumlah spora setiap genus FMA pada permudaan alam nyamplung tingkat semai (The average number of spores of each genus AMF on nyamplung natural regeneration of the seedling level).

\begin{tabular}{|c|c|c|c|c|c|c|c|c|}
\hline \multirow[t]{2}{*}{ Genus } & \multirow[t]{2}{*}{ Ulangan } & \multicolumn{6}{|c|}{$\begin{array}{c}\text { Rata-rata jumlah spora pada setiap tinggi permudaan alam } \\
\text { tingkat semai }(\mathrm{cm})\end{array}$} & \multirow{2}{*}{$\begin{array}{c}\text { Rata- } \\
\text { rata }\end{array}$} \\
\hline & & 10 & 30 & 60 & 90 & 120 & 150 & \\
\hline \multirow{4}{*}{ Glomus } & 1 & 235 & 308 & 339 & 325 & 369 & 423 & 333 \\
\hline & 2 & 308 & 375 & 645 & 753 & 754 & 764 & 600 \\
\hline & 3 & 391 & 572 & 787 & 885 & 992 & 1518 & 858 \\
\hline & $\begin{array}{c}\text { Rata- } \\
\text { rata }\end{array}$ & 312 & 418 & 590 & 655 & 705 & 902 & 597 \\
\hline \multirow{4}{*}{ Gigaspora } & 1 & 9 & 9 & 17 & 11 & 9 & 17 & 12 \\
\hline & 2 & 13 & 17 & 14 & 21 & 20 & 17 & 17 \\
\hline & 3 & 9 & 12 & 13 & 15 & 15 & 32 & 16 \\
\hline & $\begin{array}{l}\text { Rata- } \\
\text { rata }\end{array}$ & 10 & 13 & 15 & 15 & 15 & 22 & 15 \\
\hline \multirow{4}{*}{ Scutellospora } & 1 & 3 & 3 & 5 & 1 & 3 & 4 & 3 \\
\hline & 2 & 5 & 5 & 7 & 5 & 4 & 2 & 5 \\
\hline & 3 & 1 & 0 & 3 & 4 & 4 & 17 & 5 \\
\hline & $\begin{array}{c}\text { Rata- } \\
\text { rata }\end{array}$ & 3 & 3 & 5 & 3 & 3 & 7 & 4 \\
\hline
\end{tabular}

Hasil penelitian padaTabel 2 tersebut menunjukkan bahwa terdapat jumlah sporaGlomus (597 buah/100 g tanah) yang lebih banyak, sedangkan Gigaspora(15 buah/100 g tanah)dan Scutellospora(4 buah/ $100 \mathrm{~g}$ tanah)ditemukan dalam 
jumlah yang sangat terbatas. Spesies Glomus sp yang banyak ini menunjukkan penyebarannya lebih luas dibandingkan dengan dua genus lainnya pada tanah daerah berpasir pantai Pecal desa Sungai Kinjil kabupaten Ketapang.Hasil ini memiliki persamaan dengan penelitian Nurhalisyah dan Rahmad (2012) yang menyatakan bahwa genus Glomus mempunyai penyebaran yang paling luas, kemudian diikuti dengan genus Gigaspora, sedangkan untuk genus Acaulospora dan Scutellospora penyebarannya masih terbatas. Selain itu Glomus merupakan genus FMA yang memiliki daya adaptasi tinggi terhadap lingkungan ekstrim termasuk pada lingkungan tanah berpasir dimana unsur hara P nya masih terikat.

Hubungan populasi spora dengan ukuran tinggi tanaman penage dapat dilihat pada Tabel 1.Tabel tersebut menunjukan terjadinya peningkatan populasi spora FMA. Hal ini dikarenakan semakin tinggi tanaman, maka daerah perakaran juga ikut bertambah, terutama bagian akar sekundernya. Tanaman yang kurang unsur hara akan berasosiasi dengan FMA melalui akar sekundernya, menyebabkan semakin banyaknya hifa yang masuk ke dalam akar. Masuknya hifa dalam jumlah yang banyak ke dalam jaringan akar sekunder, menyebabkan unsur hara yang terserap oleh tanaman bertambah banyak sehingga pertumbuhan tanaman lebih terpacu. Bertambahnya jumlah spora dan meningkatnya ukuran tinggi permudaan alam ada hubunganya dengan hasil fotosintesis berupa karbohidrat yang dihasilkan oleh tanaman. Suplai karbohidrat ke fungi mikoriza dapat berpengaruh positif terhadap perkembangan fungi itu sendiri terutama dalam pembentukan spora.Hal ini sesuai dengan pernyataan Harjadi (1996) bahwa tinggi tanaman berkaitan dengan pertumbuhan daun, dimana semakin tinggi tanaman, maka daun yang terbentuk semakin banyak. Lukikariati dkk. (1996) menyatakan jumlah daun yang banyak dapat meningkatkan laju fotosintesis tanaman sehingga akumulasi fotosintat yang dihasilkan menjadi tinggi.

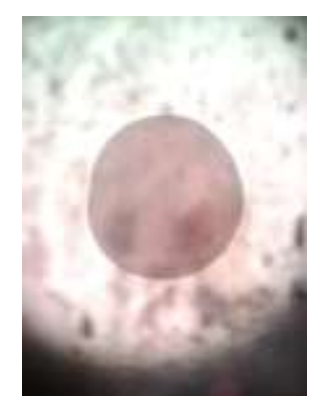

Glomus sp

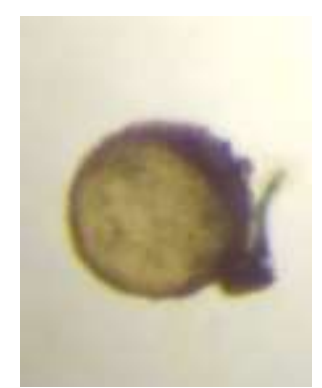

Gigasporasp

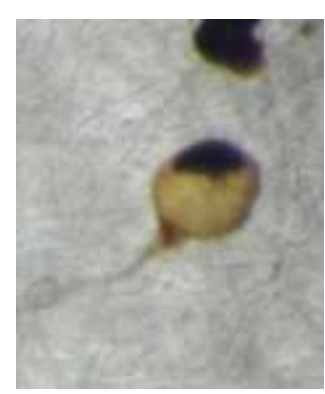

Scutellospoasp

Gambar 1. Genus FMA yang terdapat pada rhizosfer permudaan alam tingkat semai nyamplung (The AMF genus found in the natural regeneration rhizosphere of penage seedling level). 


\section{Perhitungan persen infeksi akar} Fungi Mikoriza Arbuskula (FMA)

Hasil perhitungan akar yang terinfeksi Fungi Mikoriza Arbuskula (FMA) terhadap 6 sampel akar permudaan alam penage tingkat semaidapat dilihat pada Tabel 3, sedangkan bentuk infeksinya dapat dilihat pada Gambar 2. Pada Tabel 3terlihat rata-rata persen infeksi akar permudaan alam tingkat semai penage antara 84-100\% merupakan kelas asosiasi yang tinggi (kelas 5).Tingkat infeksi terendah yaitu sebesar $84 \%$ ditemukan pada permudaan alamnyamplung tingkat semaiukuran tinggi $10 \mathrm{~cm}$ dan infeksi yang tertinggi $(100 \%)$ pada akar permudaan alam nyamplung tingkat semai dengan tinggi $150 \mathrm{~cm}$.

Tabel 3. Rata-rata persen infeksi akar pada tingkat semai permudaan alam nyamplung.(Average percentage of root infections onnyamplung seedlings levels).

\begin{tabular}{|c|c|c|c|c|c|c|}
\hline \multirow{2}{*}{$\begin{array}{l}\text { Tinggi } \\
\text { tanaman }\end{array}$} & \multicolumn{3}{|c|}{$\begin{array}{c}\text { Rata-rata \% Infeksi akar pada } \\
\text { sampel }\end{array}$} & \multirow{2}{*}{$\begin{array}{c}\text { Rata-rata } \\
\text { total \% } \\
\text { infeksi akar }\end{array}$} & \multirow{2}{*}{$\begin{array}{c}\text { Kelas } \\
\text { tingkat } \\
\text { asosiasi }\end{array}$} & \multirow{2}{*}{$\begin{array}{c}\text { Keterangan } \\
\text { tingkat } \\
\text { asosiasi }\end{array}$} \\
\hline & 1 & 2 & 3 & & & \\
\hline $10 \mathrm{~cm}$ & 90,00 & 63,33 & 100,00 & 84,44 & kelas 5 & Tinggi \\
\hline $30 \mathrm{~cm}$ & 96,66 & 100,00 & 100,00 & 98,89 & kelas 5 & Tinggi \\
\hline $60 \mathrm{~cm}$ & 100,00 & 100,00 & 100,00 & 100,00 & kelas 5 & Tinggi \\
\hline $90 \mathrm{~cm}$ & 96,66 & 100,00 & 100,00 & 98,89 & kelas 5 & Tinggi \\
\hline $120 \mathrm{~cm}$ & 100,00 & 100,00 & 100,00 & 100,00 & kelas 5 & Tinggi \\
\hline $150 \mathrm{~cm}$ & 100,00 & 100,00 & 100,00 & 100,00 & kelas 5 & Tinggi \\
\hline
\end{tabular}

Persentase infeksi lebih dari $84,44 \%$ menunjukan sudah terbentuk asosiasi dalam bentuk interaksi yang tinggi antara permudaan alam tingkat semai penage dengan FMA. Sebagaimana dikemukakan oleh Nasution $d k k$. (2013) bahwa FMA membentuk interaksi yang kompleks pada tanaman, sekaligus merupakan suatu bentuk hubungan simbiosis mutualistik, dimana tanaman mendapatkan unsur hara dan mineral yang cukup, sedangkan FMA mendapatkan karbohidrat yang dihasilkan dari proses fotosintesis tanaman. Pernyataan tersebut sesuai dengan Azcon dan Bago (1994) bahwa suplai karbon mempengaruhi proses pertumbuhan dan fungsi mikoriza pada tanaman melalui proses fotosintesis.

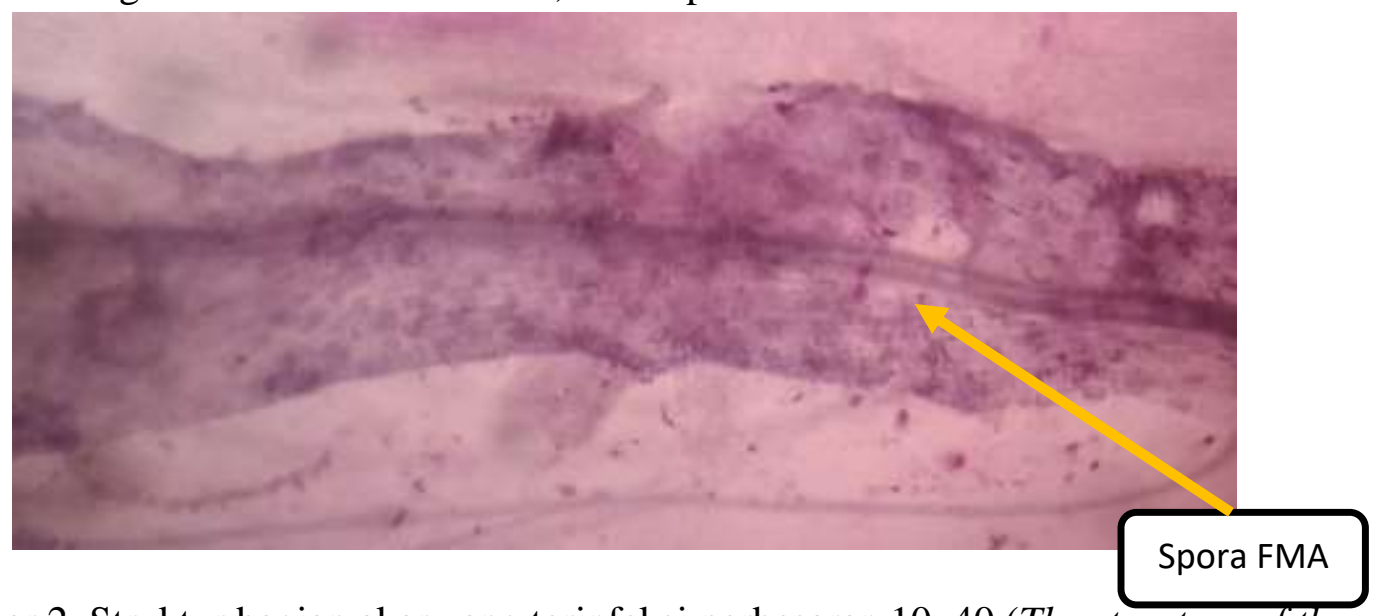

Gambar 2. Struktur bagian akar yang terinfeksi perbesaran 10x40 (The structure of the infected part of the root 10x40). 
Jika dilihat dari tingkat infeksi akar permudaan alam penage tersebut, ternyata setiap ukuran tinggi, tingkat infeksi dalam akarnya berbeda-beda. Hasil infeksi setiap ukuran tinggi tanaman yang berbeda-beda ini dapat disebabkan karena perbedaan fase perkembangan pertumbuhan FMA.Menurut Santoso (1998) terdapat tiga fase perkembangan pertumbuhan FMA, yaitu fase awal yang merupakan tahap infeksi primer, yang kedua adalah fase eksponensial dimana FMA tumbuh dan menyebar dengan cepat pada sistem perakaran, kemudian yang ketiga yaitu fase stationer yang mana kecepatan perkembangan pertumbuhan akar dan FMA akan menjadi sama.

Hasil analisis terhadap sampel tanah berpasir pada rhizosfer permudaan alam tingkat semai penage dengan ukuran tinggi $10 \mathrm{~cm}$ sampai 150 cm diketahui $\mathrm{pH}$ berkisar 4,03-6,07, kandungan Nitrogen (N-total) 0,09 0,19\%, fosfor $\left(\mathrm{P}_{2} \mathrm{O}_{5}\right)$ 725,48 -1091,73 ppm dan kalium $(\mathrm{K})$ berkisar antara $0,25-0,37 \mathrm{cmol}(+) \mathrm{kg}^{-1}$. Berdasarkan hasil analsis tersebut, ternyata penage tumbuh pada tanah berpasir yang tidak subur dengan $\mathrm{pH}$ rendah (asam) dan kandungan $\mathrm{N}$ dan $\mathrm{K}$ yang rendah. Konsentrasi fosfor $\left(\mathrm{P}_{2} \mathrm{O}_{5}\right)$ cukup tinggi, namun diduga tidak tersedia bagi tanaman penage. Asosiasi yang cukup tinggi antara tanaman penage dengan FMA menunjukkan sangat berperannya fungi tersebut dalam membantu penyerapan hara terutama fosfor. Hal ini didukung dengan adanya pernyataan dari Setiadi (1990), tanaman yang bermikoriza akan tumbuh lebih baik dari tanaman tanpa mikoriza karena mikoriza secara efektif dapat meningkatkan penyerapan unsur hara makro. Selanjutnya dikemukakan jugabahwa akar tanaman yang bermikoriza dapat menyerap unsur hara dalam bentuk terikat dan tidak tersedia bagi tanaman. Selain membentuk hifa internal, mikoriza juga membentuk hifa eksternal yang berfungsi menyerap fospor dari dalam tanah. Fospor yang telah terserap oleh hifa eksternal akan segera ditransfer ke tanaman induk sebagai inangnya.

Umumnya tanah yang memiliki ketersediaan pospor tinggi, tingkat asosiasinya terhadap FMA menjadi rendah.Sebaliknya pada penelitian ini, justru menunjukan hasil dimana konsentrasi fosfor tinggi, tingkat asosiasinya juga tinggi. Proses asosiasi yang bersifat matualistis dapat berlangsung dengan baik karena tanaman mendapatkan unsur hara (fosfor) dalam jumlah yang banyak, sedangkan FMA mendapatkan suplai hara yang cukup untuk perkembangannya. Hubungan simbiosis antara tanaman penage dan FMA mempengaruhi pertumbuhan dan perkembangan penage, sehingga dapat menghasilkan permudaan penage yang berkualitas baik, meskipun tumbuh pada tapak yang berpasir. Hal ini dikarenakan peran dari mikoriza sebagai bioprosesor dan bioaktivator di dalam tanah, yakni membantu penyerapan unsur hara dan membantu meningkatkan simpanan karbon di lapisan rhizosfer, sehingga 
meningkatkan aktivitas jasad renik dalam menjalankan proses biokimia (Nusantara dkk. 2012).

\section{Kesimpulan}

1. Hasil dari penelitian dapat disimpulkan bahwa permudaan alam tingkat semai nyamplung (Callophylluminophyllum L) yang tumbuh pada habitat berpasir di desa Sungai Kinjil (pantai Pecal) kabupaten Ketapang berasosiasi dengan fungi mikoriza arbuskula (FMA).

2. Rerata jumlah spora yang terdapat pada rhizosfer permudaan alam nyamplung tingkat semai dengan tinggi $10 \mathrm{~cm}, 30 \mathrm{~cm}, 60 \mathrm{~cm}, 90 \mathrm{~cm}$, $120 \mathrm{~cm}$, dan $150 \mathrm{~cm}$ adalah 325931 buah/100 g tanah. semakin tinggi semai, populasi spora FMA semakin bertambah.

3. Dari hasil penelitian ditemukan tiga genus FMA yaitu Glomus, Gigaspora dan Scutellosporapada tanah rhizosfer permudaan alam tingkat semai nyamplung.Jumlah spora genus Glomus ditemukan terbanyak dengan jumlah 597 buah/100 g tanah. Selanjutnya diikuti dengan genusGigasporasebanyak15

buah/100 g tanah dan terakhir genus Scutellospora sebanyak 4 buah/100 $\mathrm{g}$ tanah.

4. Asosiasi permudaan alam nyamplung tingkat semai dengan FMA termasuk dalam kategori tinggi. Rerata persen infeksi akar adalah $84,44 \%$ sampai $100 \%$ atau berada pada kelas 5. Asosiasi ini sudah terjadi pada permudaan alam penage tingkat semai sejak berukuran $10 \mathrm{~cm}$ dan masih terdapat kotiledonnya.

\section{Saran}

1. Berdasarkan hasil penelitian tersebut bahwa untuk budidaya tanaman penage, inokulasi FMA dapat dilakukan dengan menggunakan media pasir yang mengandung spora FMA.

2. Perlunya dilakukan penelitian uji efektivitas terhadap ketiga genus FMA pada tanaman penage agar ditentukan genus yang terbaik untuk diinokulasikan pada bibit penage.

\section{DAFTAR PUSTAKA}

Azcon R, Bago B. 1994. Influence of arbuskular and ericoid mycorrhiza formation on levels of photosynthetic pigments in host plant. Biol Fertil Soil 17:51-56.

Burhanuddin, Muin A, Yani A. 2012. Pengembangan Iptek Penanaman nyamplung (Callophylum spp) Untuk Produksi biofuel Bagi Masyarakat Daerah Pesisir. Laporan Penelitian Strategis Nasional. Fakultas Kehutanan Universitas Tanjungpura.

BrundrettM,Melville L, Petersoon L. 1994. Practical methods inmycorrhiza research.Mycologue Publications, p. 95- 100.

Delvian.2005. Respon Pertumbuhan dan Perkembangan Cendawan Mikoriza Arbuskula dan Tanaman terhadap Salinitas Tanah. Medan (ID): USU Repository.

Harjadi.1996. Pengantar Agronomi. Jakarta: Gramedia Pustaka Utama.. 
INVAM. 2013. International Culture Collection Of (Vesicular) Arbuscular Mycorrhizal Fungi. http://fungi.invam.wvu.edu/thefungi/classification.html. Diakses pada tanggal 11 Juli 2018.

Lukitariati, Indriyani, Susiloadi, Anwarudin. 1996. Pengaruh naungan dan konsentrasi asam indol butirat terhadap pertumbuhan bibit batang bawah manggis. Hortikultura 6(3): 220226.

Muin A. 2009. Teknologi Penanaman Ramin (Gonystylus bancanus (Miq.) Kurz) pada Areal Bekas Tebangan. Pontianak: Untan Press.

Muin A, Edi Thamrin, Burhanuddin, Muin S. 2011. Inventarisasi Potensi Tegakan Penage di Kabupaten Kayong Utara. Laporan Penelitian Kerjasama Pemerintah Daerah Kabupaten Kayong Utara dengan Fakultas Kehutanan UNTAN. Universitas Tanjungpura Pontianak.

Muin A. 2018. Potensi Pohon Penage (Callophyllum sp) Sebagai Sumber Bahan BakuBiodisel Bagi Masyarakat Pesisir Kabupaten Ketapang.Laporan Penelitian Dana Fakultas Pertanian UNTAN.Universitas Tanjungpura Pontianak.

Nasution TK, Rosmayati, Husni Y. 2013. Respon pertumbuhan dan produksi kedelai (Glycine max (1.) Merrill) yang diberi fungi mikoriza arbuskular (fma) pada tanah salin. Jurnal Online Agroekteknologi 2(1): 421-427.

Nurhalisyah, Rahmad. 2012. Identifikasi fungi mikoriza arbuskular di lahan tebu PTPN XIV serta efektifitasnya untuk meningkatkan serapan fosfat dalam menunjang produksi tebu. Agrisistem Seri Hayati 8(2): 6269.

Nurhandayani, Linda R, Khotimah S. 2013. Inventarisasi jamur mikoriza vesikular arbuskular dari rhizosfer tanah gambut tanaman nanas (Ananas comosus (1.)Merr).Protobiont 2(3): 146151.

Nusantara AD, Yudhy HB, Irdika M. 2012. Bekerja Dengan Fungi Mikoriza Arbuskula. Bogor: SEAMEO BIOTROP.

Petrus, Burhanuddin, Wulandari RS. 2013. Asosiasi Cendawan mikoriza Arbuskula (CMA) Pada Ketapang (Terminalia Catappa). Jurnal Hutan Lestari 1(3): 258267.

Priyanto A. 2013. Eksplorasi nyamplung (Calophyllum Inophyllum L.) di sebaran alamKalimantan Barat (Ketapang) untuk program pemuliaan pohon.PemuliaanTanaman 11(2): 69-78.

Santoso E. 1998. Ektomikoriza Pada Eucalyptus.Bogor: Bioteknologi IPB.

Setiadi Y. 1990. Prospek pengembangan Cendawan Mikoriza Arbuskula untuk rehabilitasi lahan kritis. Di dalam: Siregar CA, Butarbutar T, editor. ProsidingEksposeHasil Penelitian Teknik Rehabilitasi dan Reboisasi Lahan Kritis; Pekanbaru, 28 Maret 1998. Hlm 1-16.

Tolosang HB. 2011. Studi Asosiasi Cendawan Mikoriza Arbuskula 
JURNAL HUTAN LESTARI (2019)

Vol. 7 (2) : 706 - 715

pada Anakan Penage

Kayong Utara. Skripsi: Fakultas (Calophyllum inophyllum L) di Kehutanan

Universitas

Pesisir Pulau Dato Kabupaten

Tanjungpura Pontianak. 